\title{
Interaction of task readiness and automatic retrieval in task switching: Negative priming and competitor priming
}

\author{
FLORIAN WASZAK \\ Max Planck Institute for Cognitive and Brain Sciences, Munich, Germany \\ and Laboratoire de Psychologie Expérimentale, CNRS and Université René Descartes, Paris, France \\ BERNHARD HOMMEL \\ Leiden University, Leiden, The Netherlands \\ and \\ ALAN ALLPORT \\ University of Oxford, Oxford, England
}

\begin{abstract}
When subjects switch between tasks, performance is slower after a task switch than after a task repetition, even when preparation time is long. We report two experiments that support the idea that a large part of these residual task shift costs can be due to stimulus-cued retrieval of previous task episodes. We demonstrate that there are two different factors at work: (1) facilitation of response to the current distractor stimulus, appropriate to the previously relevant, competing task (competitor priming), and (2) impaired processing of previously suppressed responses (negative priming). Negative priming was contingent on the size of the stimulus set, suggesting that distractor suppression comes into effect only if the distractors are highly activated. Importantly, both types of interference interacted with task readiness: Whereas in the nondominant task (picture naming), switch and nonswitch trials were equally affected, the dominant task (word reading) showed priming effects on switch trials only. Thus, the retrieval of previous processing episodes has a selective impact on situations in which task competition is high.
\end{abstract}

People find it difficult to switch from one task to another. To investigate this issue, researchers have recently employed the so-called task-switching paradigm, in which people alternate between two choice reaction time (RT) tasks (e.g., Allport, Styles, \& Hsieh, 1994; Fagot, 1994; Goschke, 2000; Mayr \& Keele, 2000; Meiran, 1996; Rogers \& Monsell, 1995). A robust outcome of such studies is that subjects do worse on task switch trials (i.e., trials following a shift from one task to another) than on task repetition trials. This is generally referred to in the taskswitching literature as the task switch cost (TSC), although it might equally well be characterized as the task repetition benefit. Many approaches to task switching assume that TSC reflects the time needed to carry out some sort of task set reconfiguration, which is believed to include disabling the previous task (e.g., Mayr \& Keele, 2000) and/or enabling the new task (e.g., Meiran, 1996; Rogers \& Monsell, 1995; Rubinstein, Meyer, \& Evans, 2001).

The research reported in this article was carried out as part of F.W.'s doctoral studies. The authors thank Maija Kulis for collecting the data. We also thank Catherine Arrington, Geoff Ward, and an anonymous reviewer for their helpful comments on an earlier draft of this article. Correspondence should be addressed to F. Waszak, Max Planck Institute for Cognitive and Brain Sciences, Amalienstr. 33, 80799 Munich, Germany (e-mail: f.waszak@gmx.net).
Interestingly, however, even very long preparation intervals following a task cue only reduce but do not eliminate TSC, and the remaining residual TSC can be of considerable size (e.g., Allport et al., 1994; Fagot, 1994; Meiran, 1996, 2000; Meiran, Chorev, \& Sapir, 2000; Rogers \& Monsell, 1995). Indeed, in the absence of an explicit task cue, simple foreknowledge of the upcoming task has been found to benefit task switch and task repetition trials equally, thus leaving TSC unchanged (e.g., Sohn \& Anderson, 2001; Sohn \& Carlson, 2000). To account for these residual costs, reconfiguration approaches have suggested that, besides the postulated control operation, which may be carried out during the preparation interval, there is a second stage of task set reconfiguration, which cannot take effect until it is triggered by an appropriate task stimulus (e.g., Rogers \& Monsell, 1995; Rubinstein et al., 2001). This second stage is thought to complete the reconfiguration of the task set, ensuring that the appropriate processing pathways are fully enabled before response selection can proceed.

An alternative interpretation of residual TSC was suggested by Allport et al. (1994). Their task set inertia (TSI) account posits the involuntary persistence of task set activation (and/or inhibition) from the preceding trial, resulting in a positive task repetition benefit when the preceding task is repeated and a task switch cost when 
the designated task is changed. Thus, on a switch of task, involuntary carryover of the task activation/inhibition from the preceding trial competes with the upcoming task, and the additional time costs arising from this task conflict are reflected in a residual TSC. Numerous studies have confirmed the reality of these carryover effects (e.g., Altmann \& Gray, 2002; Goschke, 2000; Meiran, 2000; Ruthruff, Remington, \& Johnston, 2001; Sohn \& Anderson, 2001; Sohn \& Carlson, 2000).

More recently, this approach has been reformulated and extended (Allport \& Wylie, 1999, 2000; Koch \& Allport, in press; Waszak, Hommel, \& Allport, 2003, 2004; Wylie \& Allport, 2000). It now distinguishes between a temporary activation component - the inertial constituent focused on by Allport et al. (1994) - and a longer term, stimulus-cued retrieval (or priming) component. The latter, long-term component is thought to result from the stimulus-triggered retrieval of task-related information from previous processing episodes. The underlying idea is that, when people carry out a particular action in response to, or in the context of, a particular stimulus under a particular task goal, they encode the underlying stimulus-, response-, and task-related codes into an integrated stimulus-response (S-R) episode, or event code (Allport, 1987; Hommel, 1998; Hommel, Pösse, \& Waszak, 2000; Logan, 1988). If one or more elements of the encoded $\mathrm{S}-\mathrm{R}$ episode are then encountered again, the S-R episode is automatically retrieved. Such a mechanism is of obvious use in the natural environment, since objects often afford the same action time and again, but it can make switching between arbitrary tasks in which the same stimuli are used more difficult.

Recent studies provide considerable support for the assumption of a longer term item-specific priming component in task switching (e.g., Allport \& Wylie, 2000; Koch \& Allport, in press; Waszak et al., 2003, 2004; see also Arrington \& Logan, 2004). Since the postulated priming mechanism depends on previous encounters with particular stimuli in the context of a particular task, its investigation requires the analysis of item-specific effects across a change of tasks. The study by Waszak et al. (2003) used a technique employed also in the present experiments. Subjects orally named either the word or the picture constituent of incongruent (Stroop-like) pictureword conjunctions (e.g., the picture of a LION with the word apple superimposed on it), switching task every 3rd trial. Task preparation time was always extensive. Priming was studied, in particular, from picture naming to word reading. Within the word-reading task, subjects could encounter picture-word stimuli that had never been presented in the context of picture naming (unprimed stimuli-i.e., items with no cross-task priming), as well as picture-word stimuli that they had previously picture named ( primed items). Word-reading RTs in response to primed items were very much longer than those to unprimed items. This effect occurred even when over 200 trials intervened between the priming event and the probe, providing powerful new evidence that the cog- nitive system stores memory traces that result from past processing episodes, linking together information about stimuli, responses, and tasks, and that these traces are automatically retrieved when one of its constituents is encountered again (Hommel, 1998; Hommel et al., 2000; Koch \& Allport, in press; Waszak et al., 2003, 2004).

However, Waszak et al. (2003) obtained these betweentasks priming effects (from picture naming to word reading) on task switch trials only; in contrast, on task repetition trials, word-reading RTs were identical for both primed and unprimed items. Thus, it appears that betweentasks priming can have greatly enhanced effects under conditions of task switching. Whatever the mechanism, the effect of this interaction was that item priming greatly increased the TSC. In reporting these results, Waszak et al. (2003) emphasized the theoretical implications of this observation for theories of executive, or top-down, control (e.g., Rogers \& Monsell, 1995; Rubinstein et al., 2001). In the present article, however, our interest is not only on how priming can influence task switching, but also on how the conditions of task switching can influence priming. In other words, we are interested in the interaction of factors traditionally labeled bottom up and top down.

Bottom-up and top-down processes are commonly explored with different experimental techniques. For example, voluntary (top-down) processes have been investigated extensively with the task-switching paradigm mentioned above. The main question addressed by studies in which this technique is used is how the cognitive system controls performance when the environment affords several actions and, therefore, performance cannot be simply stimulus driven. In contrast, involuntary (bottom-up) influences on performance have been explored typically with priming techniques, which focus on effects driven by current stimuli and their associations and/or by immediately preceding processing states. The purpose of the present study was to examine the mutual impact of (top-down) task readiness and of two kinds of (bottomup) priming. In the experiments to be reported here, we used the same techniques as Waszak et al. (2003) - that is, we used speeded, selective naming tasks in response to picture-word Stroop stimuli. Top-down control was manipulated by the variable of trial-to-trial task repetition versus task shift; we combined this manipulation with two kinds of (item-specific) long-term repetition priming.

\section{Negative Priming and Competitor Priming}

In the study by Waszak et al. (2003), there were at least two different ways in which previous experience with the current stimulus, in the context of one task, might have affected later performance in a different task. Suppose, for instance, that the subject is required to name the word element (apple), in the LION-apple picture-word compound, after having earlier named the picture (LION). Naming the picture in the presence of a word distractor may have required suppression of the competing (word- 
reading) response, and it could have been this prior suppression of the irrelevant response that impaired later response to the same stimulus. Thus, saying "lion" on the first occasion might involve suppressing the competing response, "apple," so that it is more difficult to retrieve the latter response to apple later on. Such a suppress-say situation and the performance deficits it produces are known as negative priming (Neill, 1977; Tipper, 1985; for overviews, see Fox, 1995; May, Kane, \& Hasher, 1995).

Some influential models of negative priming posit a short-lasting inhibitory process (e.g., Tipper, Weaver, \& Houghton, 1994). However, not all accounts of negative priming are based on direct inhibition. In particular, Neill and colleagues (Neill, 1997; Neill \& Valdes, 1992; Neill, Valdes, Terry, \& Gorfein, 1992) have suggested a retrieval account of negative priming. Ignoring a distractor, Neill and colleagues assume, creates an episodic memory trace that includes information that this distractor is to be ignored. If the same episodic trace is reactivated on a later encounter with the same distractor, ignoring it again is facilitated. This will benefit performance if the same stimulus element is again to be ignored but will impair performance if it is now a target requiring a response. Hence, the retrieval account attributes the effect to a memory trace, which may survive many intervening trials, consistent with the betweentasks priming effects observed by Waszak et al. (2003) and earlier by Allport and Wylie (2000).

However, negative priming is not the only possible way that previous experience could generate item-specific interference when a subject switches from one task to another. Suppose that a subject had responded to the LION-apple compound, in an earlier picture-naming trial, as "lion." This event, we have assumed, results in a specific memory trace linking stimulus, task context, and response. If the same compound stimulus is presented again, but now in the context of word reading, it may trigger involuntary retrieval of this earlier, picture-naming episode, reactivating the (now inappropriate) picturenaming process in response to the current (picture) distractor, thus competing for action control with the appropriate word-reading response. In other words, previous experience in one task may affect later performance in a different task, by means of what we call competitor priming (cf. Warren, 1972, 1974), as well as by means of negative priming. Note that both competitor priming and negative priming, as described above, result from the same underlying mechanism. Both are due to the retrieval of previous processing episodes, cued by the currently presented stimuli. The difference is simply that, in the case of negative priming, the retrieved episode encodes the current target as a to-be-ignored distractor, whereas in the case of competitor priming, the retrieved episode represents the current distractor as a target item, along with its associated task and task-relevant response.

To summarize, there is already considerable evidence that task-switching performance can be affected by previous encounters with the same stimuli in the context of a different, competing task (Allport \& Wylie, 1999, 2000; Koch \& Allport, in press; Waszak et al., 2003, 2004). The main empirical question, for the experiments to be reported here, is what kind of item-specific retrieval is responsible. Is it negative priming, competitor priming, or both? Moreover, in contrast to the study by Waszak et al. (2003), the theoretical focus in the present report is on the reciprocal influence of top-down control and bottom-up priming processes - in particular, on how (bottom-up) priming is affected by (top-down) task readiness.

\section{EXPERIMENT 1}

The first experiment was designed to provide independent estimates of the contribution of between-tasks negative priming and competitor priming to residual TSC. We adopted the general experimental logic underlying Waszak et al.'s (2003) study. Subjects either vocally read the word or named the picture in response to Strooplike word-picture compounds. In our earlier studies, the respective contributions of competitor priming and negative priming could not be separated, because the same, fixed picture-word conjunctions were presented in both prime and probe trials. In the experiments to be reported here, picture and word elements were recombined in different conjunctions on prime and probe trials, so that competitor-priming and negative-priming effects could be assessed separately. Note that the word and the picture elements in these compound picture-word stimuli were always incongruent, in both prime and probe trials. There were no presentations of pictures or words alone.

As in Waszak et al. (2003), our main focus was on the effects of a task shift from picture naming to word reading. Between-task, item-specific priming was manipulated by presenting a given element (either a word or a picture) of these picture-word conjunctions first in the context of picture naming and then, a second time, after a variable number of intervening trials in the context of the word-reading task. Picture naming was thus designated as the prime task and word reading as the probe task. (The original motivation for this was to investigate the very large TSC effect when switching from Stroop color naming to word reading; Allport et al., 1994.)

The experiment was run in two successive phases. In the first, baseline phase, word-reading performance alone was probed under pure task conditions, prior to any exposure to the picture-naming task. In the second, taskalternating phase, the subjects alternated predictably between picture $(\mathrm{P})$ naming and word $(\mathrm{W})$ reading every second trial (PP WW PP WW ...). The stimuli were presented in runs of just two trials, each run preceded by a task cue.

Inclusion of the word-reading baseline condition was motivated by the observation that performance on task repetition trials may not represent a condition of full or optimal reconfiguration for the current task (e.g., Allport \& Wylie, 1999, 2000). The optimum control for this 
purpose is performance under pure task conditions, prior to any exposure to the competing (picture-naming) task. An additional reason for including the baseline condition was to control for the occurrence of first trial, or restart RT costs, independently of any requirement to switch tasks (e.g., Wylie \& Allport, 2000).

In the task-alternating phase, stimulus sequences were designed to provide four different between-tasks priming conditions, to assess independently the effects of negative priming and competitor priming from the picturenaming task in subsequent word-reading performance. The four priming conditions were as follows. (1) In the unprimed condition (the $U$ condition), neither the word nor the picture element in the word-picture conjunctions presented for word reading had previously occurred in any picture-naming trial. (2) In the negative-priming condition (the NP condition), the word element of the word-picture conjunction had previously appeared as a distractor in a picture-naming trial, whereas the picture element had not been presented for picture naming before. The NP condition thus afforded possible negative priming between tasks, but not competitor priming. (3) In the competitor priming condition (the $C P$ condition), the picture element had been named in an earlier picturenaming trial, whereas the word had never appeared as a distractor during picture naming. The $\mathrm{CP}$ condition thus afforded possible competitor priming, but not negative priming. Finally, (4) in the $N P+C P$ condition, both the picture and the word elements had appeared previously in the context of picture naming - as picture target and word distractor, respectively - but separately, in different picture-naming trials. The NP $+\mathrm{CP}$ condition thus allowed for both between-tasks negative priming and competitor priming. Note that two of these four conditions represented replications of the conditions employed by Waszak et al. (2003). The present U condition corresponded to their unprimed condition, whereas the present $\mathrm{NP}+\mathrm{CP}$ condition corresponded essentially to their primed condition.

\section{Method}

Subjects. Eighteen subjects, 5 males and 13 females with a mean age of 23 years, took part for a fee of DM 15 (€ 7.5). The reactions of 1 subject were exceptionally slow, so we excluded his/her data from the analyses. The experiment lasted about $1 \mathrm{~h}$. All the subjects were native German speakers, and none reported having participated in a similar experiment.

Apparatus and Stimuli. The experimental material consisted of 72 line drawings and 72 German words, which were presented as picture-word conjunctions on a 17-in. EIZO FlexScan 9080i-M monitor. They were presented in black on a white background at the center of the screen. The mean extension of the line drawings was approximately $1.9^{\circ}$ in the vertical and $1.9^{\circ}$ in the horizontal dimensions. Example stimuli are shown in Figure 1.

The line drawings and corresponding normative data were obtained from the Snodgrass-Vanderwart set of standardized pictures (Snodgrass \& Vanderwart, 1980). The words and their norms were drawn from the CELEX lexical database (Burnage, 1990). The following constraints applied to the selection of stimulus items: (1) No pictured object was also presented as a word, and vice versa, (2) the picture names and the written words were all of either one or two syllables, (3) the pictures were conceptually and linguistically as unambiguous and familiar as possible, and (4) the imageability and frequency of the words were chosen to be as high as possible.

In contrast to Waszak et al. (2003), we did not use fixed pictureword conjunctions. Instead, picture and word elements from different subsets were recombined, as between prime and probe trials, according to the different priming conditions described above. For this purpose, the 72 pictures and 72 words were divided into three subsets of 24 pictures and 24 words each. The three subsets were matched for image agreement, familiarity, and complexity with regard to the picture elements, for syllable length and name agreement with regard to the picture names, and for syllable length and word frequency with regard to the word elements. ${ }^{1}$

Design. Counterbalanced across subjects, the three item subsets ( 24 pictures and 24 words each) were allocated for inclusion in different picture-word compounds - to appear, respectively, in either one or the other or in both tasks, as follows. One subset of picture and word elements was presented only in the context of the wordreading task; these are referred to as the WordOnly set. Another item subset appeared only in the context of picture naming; these are referred to as the PicOnly set. The third item subset, to be used for the between-tasks priming manipulations, appeared in both the picture-naming and the word-reading tasks and are referred to as the Pic\&Word set.

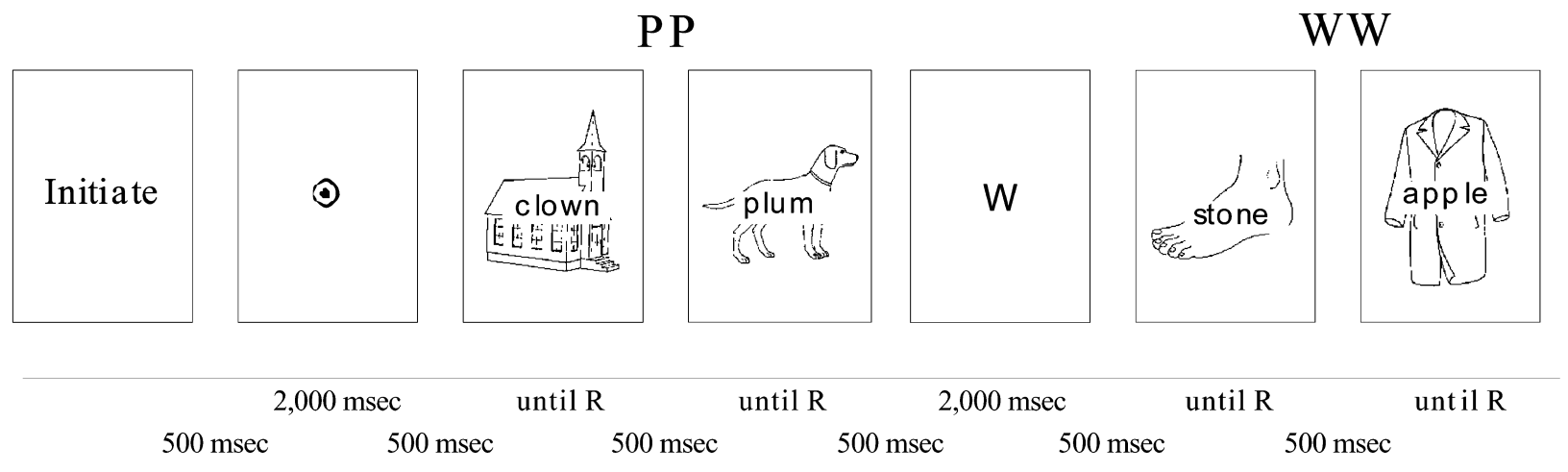

Figure 1. Stimulus sequence for two picture-naming trials followed by two word-reading trials, forming one 4-trial miniblock (see the text). $P$, picture; $W$, word. 
(A) Stimulus elements

$\begin{array}{clcc}\text { Picture: } & \text { Word: } & & \\ \text { WordOnly } & \text { WordOnly } & \longrightarrow & \text { Unprimed } \\ \text { WordOnly } & \text { Pic\&Word } & \longrightarrow & \text { Negatively primed } \\ \text { Pic\&Word } & \text { WordOnly } \longrightarrow & \text { Competitor primed } \\ \text { Pic\&Word } & \text { Pic\&Word } & \longrightarrow & \begin{array}{c}\text { Negatively and } \\ \text { Competitor primed }\end{array}\end{array}$

Figure 2. The four priming conditions in Experiment 1. The left side (A) shows from which set (Pic\&Word or WordOnly) the picture and word elements are drawn in order to produce the four priming conditions $(B)$, as described in the text. (1) Unprimed condition: Neither the word nor the picture, in the compound stimulus presented for word reading, has appeared in the context of picture naming (both picture and word from the WordOnly set). (2) Negative priming condition: The target word presented for word reading has appeared previously as a distractor in a picture-naming trial; however, it is combined with a picture that has not been presented in picture naming (picture from the WordOnly set, word from the Pic\&Word set). (3) Competitor priming condition: The picture distractor, in the compound stimulus presented for word reading, has appeared previously as the picture target in a picture-naming trial, but it is combined with a word that has never appeared as a distractor in any picture-naming trial (picture from the Pic\&Word set, word from the WordOnly set). (4) Negative and competitor priming condition: Both the distractor picture and the target word for the word-reading trial have been presented in prior (but different) picture-naming trials (both picture and word from the Pic\&Word set).

At the beginning of the experiment, the subjects worked through a baseline phase of pure task word reading. In this phase, all the items from the WordOnly and Pic\&Word sets were presented. The word and picture elements were randomly paired. When all the elements had appeared once, they were randomly recombined and presented again, for three complete iterations, giving a total of 144 trials. (Note that any item repetition benefit from the baseline phase should affect both these item sets equally; hence, inclusion of the baseline phase cannot differentially affect the between-tasks priming conditions described below. This conclusion is supported by Waszak et al. (2003), who reported similar results with and without an initial baseline phase.)

In the task-alternating phase, both picture and word elements from the WordOnly set (which were never presented in the context of picture naming) served as unprimed stimuli for word reading. Picture and word elements from the Pic\&Word set (presented in both tasks) constituted primed items for word reading. (Note that, in all cases, priming refers to priming between tasks - specifically, from picture naming to word reading.) Figure 2 exemplifies the four priming conditions. The figure shows how the elements of the WordOnly and Pic\&Word subsets were combined to produce the four stimulus conditions presented for word reading. (1) A picture element from the WordOnly set, combined with a word element from the WordOnly set, constituted an unprimed stimulus (the U condition). These compound picture-word stimuli were unprimed in that neither the word nor the picture had appeared in the context of picture naming. (2) A picture element from the WordOnly set, combined with a word element from the Pic\&Word set, constituted a negatively primed stimulus (the NP condition). The compound stimulus was (only) negatively primed because the target word had appeared previously as a distractor in a picture-naming trial; however, it was combined with a picture that had not been presented in picture naming. (3) A picture element from the Pic\&Word set com- bined with a word element from the WordOnly set constituted a competitor-primed stimulus (the CP condition). The compound stimulus was (only) competitor primed because the picture distractor had appeared previously as the picture target in a picture-naming trial, but it was combined with a word that had never appeared as a distractor in any picture-naming trial. (4) Finally, a picture element from the Pic\&Word set combined with a word element also from the Pic\&Word set constituted a competitor-primed and negatively primed stimulus (the NP+CP condition). This was because both the distractor picture and the target word had been presented in prior picture-naming trials.

For picture naming in the alternating phase, an item from the Pic\&Word set was always combined with an item from the PicOnly set (e.g., a picture from Pic\&Word combined with a word from PicOnly, and vice versa). Therefore, the same picture-word conjunctions never appeared in both picture naming and word reading.

The sequence of stimuli was designed so that each priming element, either a picture or a word (from the Pic\&Word set), occurred first in the context of picture naming and then, a minimum of 4 and a maximum of 14 trials later, for a second occasion in the context of word reading. (The median number of intervening trials between prime and probe occurrence, for all three priming conditions, was 9.) Word and picture elements from the WordOnly and PicOnly sets were presented once each.

When all the word and picture elements had been presented once each (and Pic\&Word elements twice each: once in picture naming and once in word reading), for a total of 96 trials, this represented one complete iteration of the experiment. The elements within each of the three item sets were then rerandomized, separately for each subject, to generate new picture-word conjunctions. (However, WordOnly elements remained as WordOnly elements, PicOnly elements remained as PicOnly elements, and Pic\&Word elements remained as Pic\&Word elements.) The procedure was repeated for four iterations. 
Table 1

Experiment 1: Word-Reading Baseline and Picture-Naming Reaction Times (RTs, in Milliseconds, With Standard Errors) and Error Rates (ERs) as a Function of Trial Position

\begin{tabular}{lllllc}
\hline & & Trial & RT & $S E$ & ER (\%) \\
\hline Word baseline & Overall & 1st & 516 & 26 & 0 \\
& & 2nd & 490 & 20 & 0 \\
Picture naming & CP & 1st & 818 & 34 & 0.7 \\
& & 2nd & 783 & 18 & 0.4 \\
& NP & 1st & 824 & 31 & 0.6 \\
& & 2nd & 779 & 22 & 0.4
\end{tabular}

Note-CP, competitor priming; NP, negative priming.

Procedure. At the beginning of the session, the subjects were familiarized with the word-reading task, using stimuli not used in the actual experiment. The subjects were instructed to respond vocally as quickly and accurately as possible.

For the 144 baseline word-reading trials, the stimuli were presented in runs of just two trials, each run preceded by a task cue. Each run (of two trials) began with the presentation of the task cue (the letter "W" for word reading) for 2,000 msec. The "W" cue extended $1.4^{\circ}$ vertically and $1.3^{\circ}$ horizontally. There was then another blank interval of $500 \mathrm{msec}$ before the onset of the first picture-word stimulus. The stimulus remained on screen until the subject's response, which triggered another blank interval of $500 \mathrm{msec}$, followed by the presentation of the second stimulus. When the subject had responded to the second stimulus, the screen again went blank for $500 \mathrm{msec}$, and the procedure was repeated, commencing with the presentation of the task cue.

After completion of the baseline word-reading phase, the subjects were instructed for and familiarized with the alternating phase, using stimuli not presented in the actual experiment. In the alternating phase, successive trials were performed in self-paced, fourtrial miniblocks: two picture-naming trials followed by two wordreading trials (PP WW). Figure 1 illustrates the stimulus sequence. Each four-trial miniblock started with a to-be-confirmed "Initiate" prompt. When the subject responded to this prompt, the screen went blank for $500 \mathrm{msec}$, followed by the task cue for picture naming for $2,000 \mathrm{msec}$. The picture-naming task cue was a nonalphanumeric symbol, a circle with a dot in the middle; the circle was the same size as the cue for word reading. After another blank interval of $500 \mathrm{msec}$, the first picture-word stimulus was presented for picture-naming. It remained on the screen until the naming response, which triggered another blank interval of $500 \mathrm{msec}$, followed by the presentation of the second stimulus. After the response to the second stimulus of the PP run, the screen again went blank for $500 \mathrm{msec}$, followed by presentation of the "W" task cue for 2,000 $\mathrm{msec}$ for word reading, indicating the start of the WW run, and a further 500msec blank interval. Thus, the response-stimulus interval between $\mathrm{PP}$ and WW runs was $3,000 \mathrm{msec}$. The subjects were encouraged to use this 3,000 -msec interval to prepare for the upcoming task. After the subject had completed the two WW trials, the "Initiate" prompt for the next miniblock appeared.

After 24 self-paced miniblocks - that is, a total of 96 trials - all the picture and word elements had been presented once each, except for primed items, which occurred twice each, once in the context of picture naming and then a second time in the context of word reading. This concluded one complete iteration (one cycle) of the experiment.

\section{Results}

Overall, accuracy was very high. Error RTs and RTs triggered prematurely by the subject's breath or by involuntary vocalizations were excluded from the analysis. The error pattern did not counteract the RT pattern; thus, a speed-accuracy tradeoff can be excluded. Only RTs for correct trials were retained for further analysis, in which $p<.05$ was adopted as the significance criterion. Table 1 shows the overall RTs and error rates for the word-reading baseline. The experiments reported here were not designed to test priming from word reading to picture naming. However, as was mentioned above, for picture naming, items from the Pic\&Word set were always combined with items from the PicOnly set (e.g., a picture from Pic\&Word with a word from PicOnly and vice versa). Hence, in picture naming, there are two types of stimuli: (1) stimuli for which the distractor word has been primed in word reading $(\mathrm{CP})$ and (2) stimuli for which the target picture has been presented in word reading as a distractor (NP). Table 1 also shows RTs and error rates for picture naming in the alternating phase separately for these competitor-primed and negatively primed items. However, our focus is on Figure 3, which shows RTs and error rates for word reading in the alternating phase.

Picture naming. A $t$ test comparing overall picturenaming RTs on first and second trials confirmed the first-trial RT costs to be significant $(p<.02)$. There were no reliable differences between picture naming in response to competitor-primed items, as compared with negatively primed items $(p s>.3)$. We will return briefly to this question in Experiment 2.

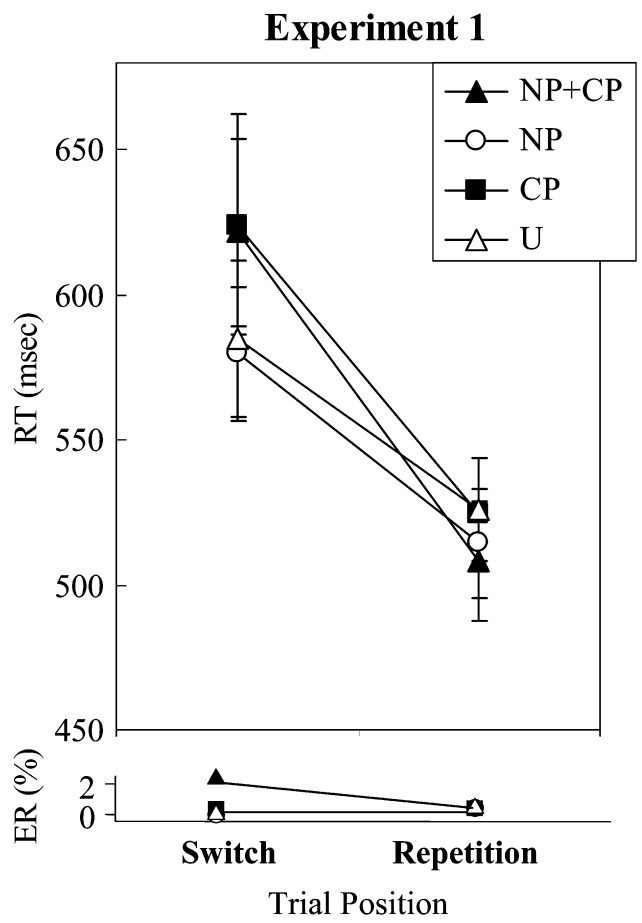

Figure 3. Experiment 1: word reading in the alternating phase as a function of trial position (first [switch] or second [repetition]) and priming condition (NP+CP, CP, NP, or U). Error bars represent the standard errors of the means. RT, reaction time; ER, error rate. 


\section{Experiment 1}

\section{(A) Competitor-Priming Component}

$\mathrm{CP}$ in $\mathrm{msec}$

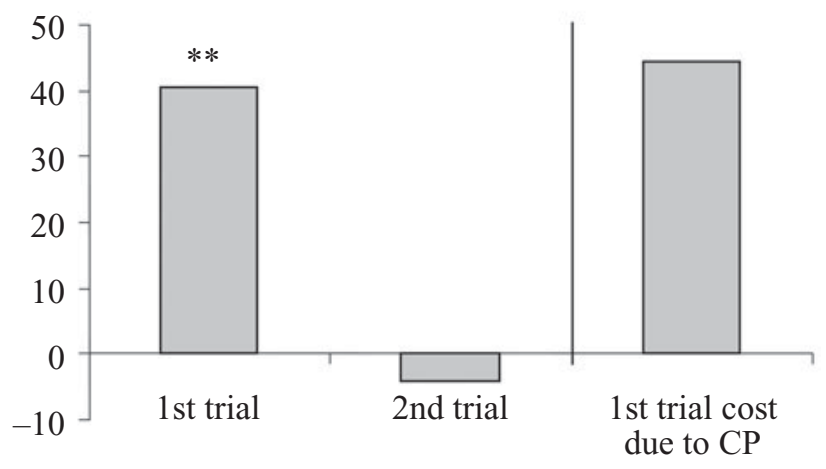

(B) Negative-Priming Component

$\mathrm{NP}$ in msec

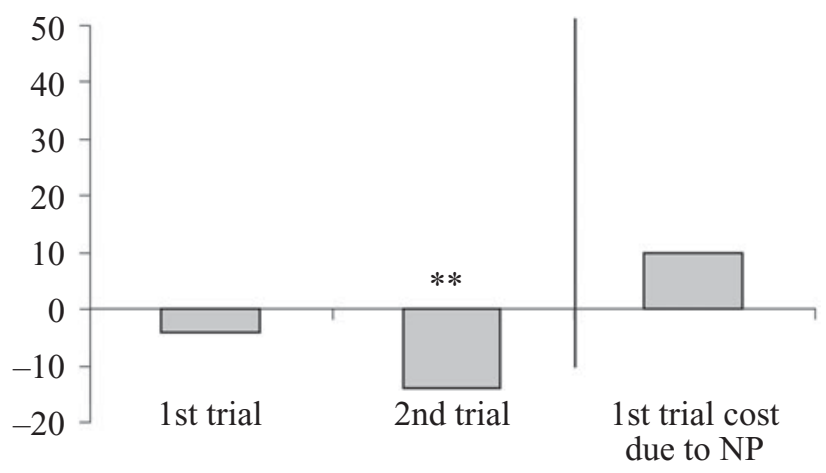

Figure 4. Experiment 1: word reading in the alternating phase. The figure shows (left panel) the two priming effects, separated for first and second trials, and (right panel) the portion of the first-trial RT cost (or task-switching cost [TSC]) that is due to the corresponding priming component. (A) Competitor-priming (CP) component: $\{[R T(N P+C P)-R T$ $(\mathrm{NP}])+[\mathrm{RT}(\mathrm{CP})-\mathrm{RT}(\mathrm{U})]\} / 2$, and $\{[\mathrm{TSC}(\mathrm{NP}+\mathrm{CP})-\mathrm{TSC}(\mathrm{NP})]+$ [TSC (CP) - TSC (U)] $\} / 2$. (B) Negative-priming (NP) component: $\{[R T$ $(\mathrm{NP}+\mathrm{CP})-\mathrm{RT}(\mathrm{CP})]+[\mathrm{RT}(\mathrm{NP})-\mathrm{RT}(\mathrm{U})]\} / 2$, and $\{[\mathrm{TSC}(\mathrm{NP}+\mathrm{CP})-$ TSC(CP)] + [TSC(NP) - TSC(U)] $/ 2$. U, unprimed. One-tailed $t$ tests: $* * p<.01$.

Word-reading baseline phase. The baseline showed a reliable first-trial RT cost of $25-30 \mathrm{msec}$ for both item subsets (cf. Wylie \& Allport, 2000). An analysis of variance (ANOVA) was performed on the baseline phase with stimulus subset (for the target word: WordOnly vs. Pic\&Word), and trial position (1 vs. 2) as factors. Trial position produced the only significant effect $[F(1,16)=$ $\left.11.467, M S_{\mathrm{e}}=1,015.461, p<.01\right]$.

Word reading in the alternating phase. The appropriate ANOVA included as factors the independent variables negative priming (primed vs. unprimed), competitor priming (primed vs. unprimed), and trial position ( 1 vs. 2 ). Two significant main effects were reliable [competitor priming, $F(1,16)=5.701, M S_{\mathrm{e}}=1,978.65, p<.05$; trial position, $F(1,16)=33.83, M S_{\mathrm{e}}=7,151.69, p<$ $.001]$, accompanied by a highly significant interaction of competitor priming and trial position $[F(1,16)=9.32$,
$\left.M S_{\mathrm{e}}=1,804.77, p<.001\right]$. A priori $t$ tests confirmed the first-trial RT costs to be significant for all conditions ( all $p \mathrm{~s}<.001$ ). The results of $t$ tests comparing the different conditions are shown in Figure 4.

\section{Discussion}

Experiment 1 produced three important outcomes. First, as is obvious from Figure 3, we were able to replicate the main findings of Waszak et al. (2003). If we compare word-reading RTs in the NP $+\mathrm{CP}$ condition (which corresponds approximately to Waszak et al.'s primed condition) with those in the $\mathrm{U}$ condition (which corresponds to Waszak et al.'s unprimed condition), we see a very large increase of switching costs. Again, this modulation of residual TSC by prior experience was observed even though a median of nine trials intervened between the presentations of the prime and the probe, 
thus supporting a retrieval-based account of the priming effect.

The second important observation concerns the role of competitor priming. There are two possible contrasts that reflect this kind of priming. First, the competitorprimed condition (CP) can be contrasted with the unprimed condition (U). This difference indicates the extent to which competitor-primed stimuli resulted in larger RTs than did completely unprimed stimuli. Second, the NP $+\mathrm{CP}$ condition can be contrasted with the NP condition. This difference indicates the extent to which the stimuli that were both negatively primed and competitor primed resulted in larger RTs than did the stimuli that were negatively primed only. The bars in the left part of Figure 4A represent the mean of these two contrasts. As is shown in the left part of Figure 4A, there was a large competitor-priming effect on first trials, which then disappeared on Trial 2. Thus, as in the study by Waszak et al. (2003), the impact of priming was restricted to the task switch trial, so that the contribution of competitor priming to the overall residual TSC was pronounced (see the right panel of Figure 4A).

Third, we found no evidence for any effect of longterm (between-tasks) negative priming. Again, there are two possible contrasts reflecting this kind of priming. First, the contrast between the NP condition and the $\mathrm{U}$ condition indicates the extent to which negatively primed stimuli resulted in larger RTs than did completely unprimed stimuli. Second, the contrast between the NP $+\mathrm{CP}$ condition and the $\mathrm{CP}$ condition signifies the extent to which competitor-primed and negatively primed stimuli resulted in larger RTs than did stimuli that were competitor primed only. Again, the bars in the left part of Figure 4B represent the mean of these two contrasts. As Figure 4B shows, if anything, there was evidence of positive priming. ${ }^{2}$ The right panel of Figure 4B shows the portion of the TSC that can be attributed to negative priming. We note that this lack of any impact of negative priming on TSC conflicts with the findings of Allport and Wylie (2000), an issue we will return to in Experiment 2.

Since each Pic\&Word item was primed and then probed a total of four times over the four successive iterations of the experiment, the observed competitorpriming effects could have been cumulated over the four cycles. However, the priming effect, in fact, showed no cumulative increase between the first and the second halves of the experiment (Cycles 1 and 2, as compared with Cycles 3 and 4). Similarly, Waszak et al. (2003) found approximately the same size of priming from picture naming to word reading in all item iterations, including the first. Thus, a single picture-naming presentation is sufficient to result in a large priming effect on word reading.

In summary, Experiment 1 revealed a solid competitorpriming component of the item-specific interference, whereas the contribution from negative priming was negligible. This suggests that the observation by Waszak et al. (2003) of item-specific priming effects on task switching can be attributed to memory traces linking previous target stimuli to previous tasks and/or responses. In contrast, distractor word inhibition in picture naming, if it occurred, had no measurable priming effect on later word reading.

\section{EXPERIMENT 2}

The outcome of Experiment 1 did not provide any evidence for a critical role of longer term negative priming in residual TSC. In view of Allport and Wylie's (2000) findings, this result was somewhat unexpected. In Allport and Wylie's Experiment 5, subjects alternated between short runs of color naming and word reading in response to incongruent color-word conjunctions - that is, Stroop-like RT tasks, as used here. Allport and Wylie's two word-reading conditions corresponded to our $\mathrm{NP}+\mathrm{CP}$ and $\mathrm{CP}$ conditions. Hence, any RT difference between those two conditions could be due only to negative priming. In fact, their Experiment 5 revealed a first-trial RT cost of about $220 \mathrm{msec}$ for negatively primed stimuli, as compared with $140 \mathrm{msec}$ for stimuli that were not negatively primed, whereas no such difference was observed on repeat trials. Thus, according to our terminology, Allport and Wylie found a substantial increase in TSC reflecting between-tasks, item-specific negative priming. Why did we not find evidence for such an effect?

There are two differences between the designs of Allport and Wylie's (2000) Experiment 5 and our present Experiment 1, which might account for the conflicting results. The first and most obvious difference is that Allport and Wylie (2000) employed a rather small stimulus ensemble - namely, just eight colors and color wordswhereas in Experiment 1 of the present study, a much larger stimulus set was used ( 72 pictures and 72 words). Thus, in Allport and Wylie's experiment, subjects met the same stimulus elements time and again, whereas, in the present Experiment 1, each word or picture was encountered only infrequently: In the alternating phase, the primed stimulus elements were presented just twice per iteration of 96 trials, once in picture naming and once in word reading.

The findings of Malley and Strayer (1995) suggest that stimulus set size and the frequency with which the same stimuli are encountered may be important factors in (within-task) negative priming. As they noted, negativepriming experiments have typically involved a small set of stimuli, presented repeatedly throughout the experiment as both targets and distractors (e.g., Neill, 1977; Tipper, 1985; Tipper \& Cranston, 1985), so that it is possible that negative priming depends on frequent stimulus repetition. Malley and Strayer proposed that stimulus repetition increases the activation levels of the stimulus codes involved; this may lead to increased selection difficulty when the system has to determine which of two highly activated stimulus items is the target. They hypothesized that only under these circumstances (on prime trials) can the mechanism responsible for negative priming come into effect. To support their idea, Malley and Strayer 
conducted a series of experiments in which they compared the effects of negative priming (ignored repetition) and positive priming (attended repetition), (1) with a large stimulus set, each stimulus appearing once as a prime and once as a probe only, and (2) with a small stimulus set, each stimulus appearing frequently as prime and probe. As was expected, small sets produced robust negative priming but no positive priming, whereas large sets yielded positive priming but no negative priming. In a follow-up study, Strayer and Grison (1999) showed that the negative-priming component, obtained with small stimulus sets, increases in size the more often a prime trial distractor had been presented as a target in previous trials.

Taken together, these observations strongly suggest that the presence (and size) of the within-task negativepriming effect depends on the relative activation of distractor codes. Given that, it is no longer surprising that negative priming played a substantial role in Allport and Wylie's (2000) study, in which word distractors must have been highly activated, but not in the present Experiment 1 , in which each stimulus element appeared only infrequently. However, this account is entirely post hoc. We tested it directly in Experiment 2.

The rationale is straightforward. If the presence of negative priming in Allport and Wylie's (2000) study and its absence in our Experiment 1 were indeed due to differences in the activation levels of distractor items, and if these differing activation levels are the result of using a large or a small stimulus set, respectively, we should be able to demonstrate an effect of negative priming on switch trial performance simply by reducing the size of our stimulus set. This is what we attempted to do in Experiment 2, in which each stimulus subset (Pic\&Word, PicOnly, and WordOnly) now contained only 4 pictures and 4 words, instead of 24 .

There was also a second difference between Allport and Wylie's (2000) Experiment 5 and our Experiment 1, which we wanted to assess. In Allport and Wylie's study (and also in Malley \& Strayer, 1995) the response sets of the two tasks (color naming and word reading) overlapped, so that all the word distractors presented on color-naming trials were also possible responses in the current color-naming task. In our Experiment 1, by contrast, picture naming and word reading were performed with completely separate response sets; thus, a word distractor presented on a picture-naming trial was never a possible picture-naming response. One may think of ways in which this response set overlap in Allport and Wylie's experiment could have made response selection on prime trials more difficult, which again could have boosted the negative-priming effect. We tested this possibility in Experiment 2 by comparing a condition in which response sets overlapped, as in Allport and Wylie's study, with a condition in which they did not, as in the present Experiment 1.

\section{Method}

Thirty-six subjects, 14 males and 22 females with a mean age of 23 years, took part. They fulfilled the same criteria as those applied in Experiment 1. The method was the same as that in Experiment 1, except for the following changes. The experimental material consisted of three sets of four pictures and four words each, assigned to the three different experimental sets: Pic\&Word, PicOnly, and WordOnly. Response set overlap was manipulated between subjects. Half the subjects were presented with nonoverlapping response sets, as in Experiment 1; that is, each item set consisted of four pictures and four words that did not denote any of the pictures. For the remaining subjects, the words in each set were identical with the names of the pictures in that set; that is, each item set consisted of four pictures and four words denoting those pictures. ${ }^{3}$ However, in this condition too, the picture and the word elements were pseudorandomly combined in such a way as to produce incongruent picture-word conjunctions only.

For the baseline phase, the subjects again performed word reading in runs of 2 trials, as a pure task. This phase included 12 iterations of all the items in the Pic\&Word and WordOnly sets. The alternating phase was also run, as before, in 4-trial miniblocks (PP WW) initiated by the subject. Word and picture elements were pseudorandomly combined to generate prime trials in picture naming and subsequent probe trials in word reading. As in Experiment 1, the median lag between stimulus element repetitions in prime and probe trials was 9 intervening trials (with a range of 4-14 intervening trials). In contrast to Experiment 1, however, one complete iteration of the experiment, in which all the stimulus elements had been presented once each (PicOnly and WordOnly items) and the priming elements twice each (Pic\&Word) was just 16 trials. Eighteen iterations were conducted (a total of 288 trials). As before, stimulus elements were rerandomized, differently for each subject, but within the same Pic\&Word, PicOnly, and WordOnly sets, for each successive iteration.

\section{Results}

Overall, accuracy was very high, as in Experiment 1, and the error pattern did not counteract the RT pattern. The remaining data were treated as in Experiment 1. Table 2 shows the overall RTs and error rates for the word-reading baseline and for picture naming in the alternating phase separately for competitor-primed and negatively primed items. Figure 5 shows RTs and errors for word reading in the alternating phase. With overlapping response sets, it was possible for the response to be the same on two successive trials (viz., on a switch from picture naming to word reading, if the picture name in the picture-naming trial was the same as the word on the subsequent word-reading trial). Since this could not

Table 2

Experiment 2: Word-Reading Baseline and Picture-Naming Reaction Times (RTs, in Milliseconds, With Standard Errors) and Error Rates (ERs) as a Function of Trial Position

\begin{tabular}{cllccc}
\hline & & Trial & RT & $S E$ & ER (\%) \\
\hline Word baseline & Overall & 1st & 473 & 7 & 0 \\
& & 2nd & 452 & 7 & 0 \\
$\begin{array}{c}\text { Picture naming } \\
\text { No overlap }\end{array}$ & & & & & \\
& & 1st & 684 & 26 & 0.4 \\
& NP & 2nd & 661 & 15 & 0.4 \\
Overlap & CP & 1st & 714 & 30 & 0.3 \\
& & 2nd & 677 & 22 & 0.4 \\
& NP & 2nd & 718 & 28 & 0.9 \\
& & 1st & 743 & 12 & 0.9 \\
& & 2nd & 711 & 16 & 0.9 \\
\hline
\end{tabular}




\section{Experiment 2}

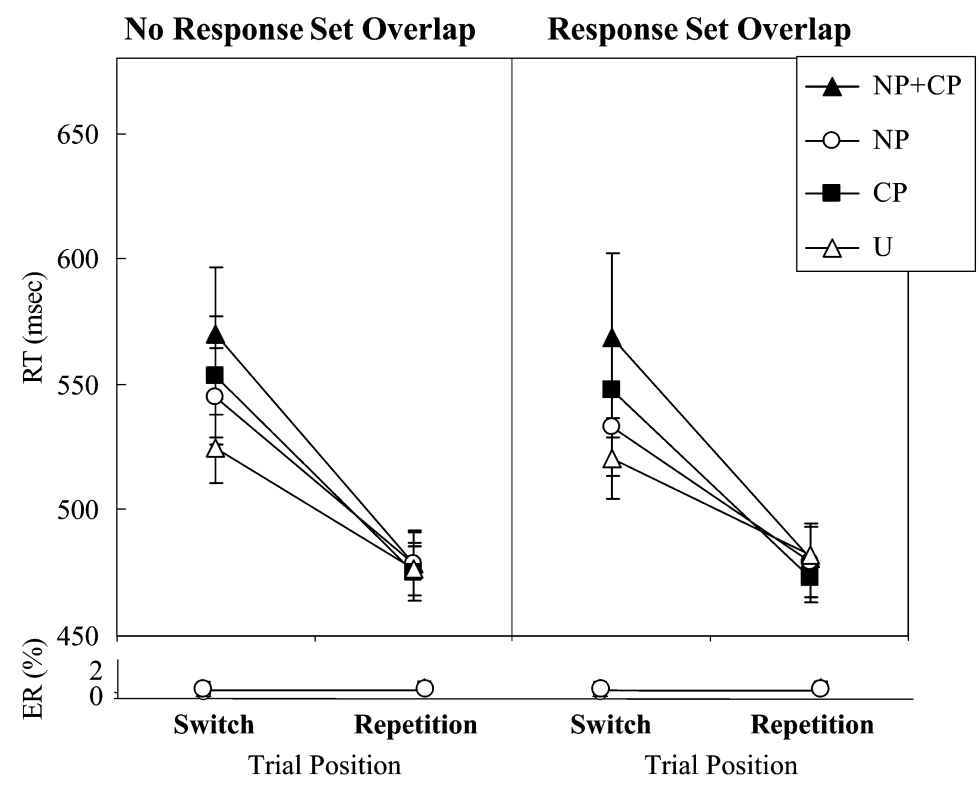

Figure 5. Experiment 2: mean reaction times (RTs) and error rates for word reading in the alternating phase, as a function of trial position (first [switch] or second [repetition]) and priming condition $(N P+C P, C P, N P$, and $U)$. Error bars represent standard errors of the means.

occur with nonoverlapping response sets, we excluded these trials from the analyses.

Picture naming. A $t$ test comparing overall picturenaming RTs on first and second trials confirmed the first-trial RT costs to be significant $(p<.01)$.

For completeness, we also will report here briefly the effects of possible between-tasks priming from word reading to picture naming. However, picture naming was designed to be the priming task, not the probe task, in these experiments; therefore, only differences between negative-priming and competitor-priming effects, if any, can be detected. In Experiment 2 (unlike in Experiment 1), there were, in fact, some RT differences in picture naming between negatively primed stimuli and competitorprimed stimuli, with negatively primed stimuli yielding longer RTs than did competitor-primed stimuli on both task switch and task repetition trials. For the subjects with no response overlap, this difference was small and unreliable ( $p$ s of $t$ tests: switch $>.11$, repetition $>.22$ ); it was somewhat larger for the group with response overlap ( $p$ s: switch $>.08$, repetition $>.06)$. This pattern of results suggests that there was some negative priming (from word reading to picture naming) in Experiment 2. The data further suggest that, for picture naming, response set overlap may be important. Recall that there was no unprimed control condition for picture naming. Therefore, the data cannot tell us whether there was also competitor priming from word reading to picture naming in Experiment 2 (in addition to negative priming, but as a smaller effect) or whether there was both negative and competitor priming in Experiment 1 (but of equal magnitude). However, these picture-naming results are incidental to the main focus of this study: the effects of between-tasks priming from picture naming to word reading.

Word-reading baseline phase. The baseline showed again a reliable first-trial RT cost for both item subsets (see Table 2). An ANOVA was performed on the baseline phase with the between-subjects factor of response set overlap (nonoverlapping vs. overlapping) and the withinsubjects factors of stimulus subset (for the target word: WordOnly vs. Pic\&Word) and trial position (1 vs. 2$)$. Trial position was the only significant effect $[F(1,34)=$ $\left.29.41, M S_{\mathrm{e}}=588.1, p<.001\right]$.

Word reading in the alternating phase. Data were analyzed using a mixed-factor ANOVA, with response set overlap as a between-subjects factor and negative priming (primed vs. unprimed), competitor priming (primed vs. unprimed), and trial position (1 vs. 2) as within-subjects factors. Three significant main effects [negative priming, $F(1,34)=4.24, M S_{\mathrm{e}}=1,819.78, p<$ .05 ; competitor priming, $F(1,34)=10.33, M S_{\mathrm{e}}=$ $1,246.08, p<.01$; trial position, $F(1,34)=71.46$, $\left.M S_{\mathrm{e}}=4,580.32, p<.001\right]$ were accompanied by two significant interactions [negative priming $\times$ trial position, $F(1,34)=5.91, M S_{\mathrm{e}}=682.27, p<.05$; competitor priming $\times$ trial position, $F(1,34)=14.87, M S_{\mathrm{e}}=1,207.49$, $p<.001]$. A priori $t$ tests confirmed the first-trial RT costs to be significant for all the conditions $(p \mathrm{~s}<.01 \mathrm{in}$ all cases). The results of $t$ tests comparing the different 
conditions are indicated in Figure 6. Competitor priming and negative priming were computed in the same way as in Experiment 1.

\section{Discussion}

Experiment 2 yielded four important results. First, the item-specific priming effect reported by Waszak et al. (2003) was replicated once again: TSC was much greater when the subjects were responding to a stimulus element that had occurred earlier in the competing picture-naming task (compare NP+CP vs. unprimed, Figure 5). Second, as is shown in Figure 6A, the effect of competitor priming on task switching was also replicated. Thus, switching to word reading took longer if the present distractor picture had been named in a previous trial than if it had not. The competitor-priming effect appeared to be smaller in Experiment 2 than in Experiment 1, but this difference was not statistically reliable ( $p s>.4)$. Third, and most important for the present purposes, significant effects of negative priming on TSC were obtained (see Figure 6B). These effects were independent of response set overlap, which suggests that the fact that they appeared in Ex-

\section{Experiment 2}

\section{(A) Competitor-Priming Component}

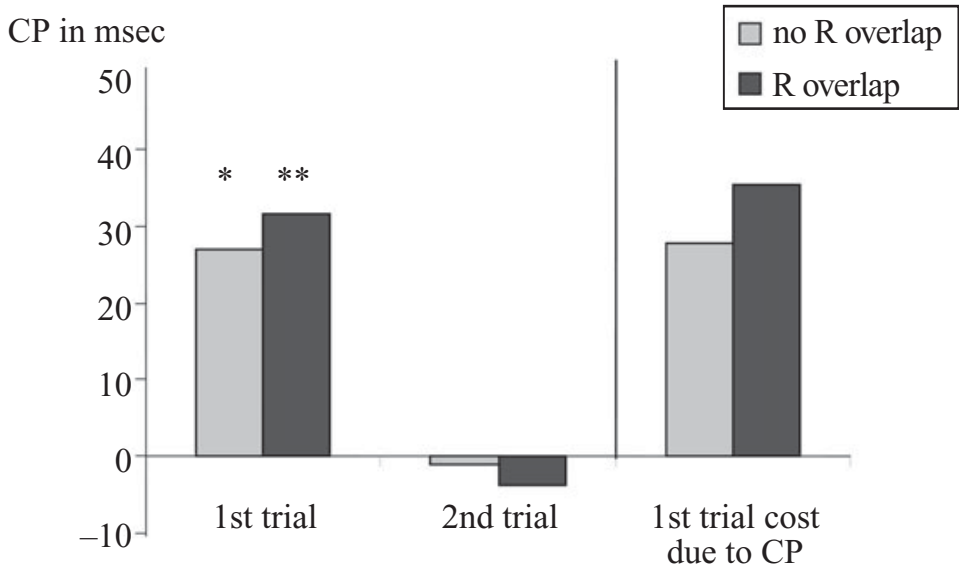

\section{(B) Negative-Priming Component}

NP in msec

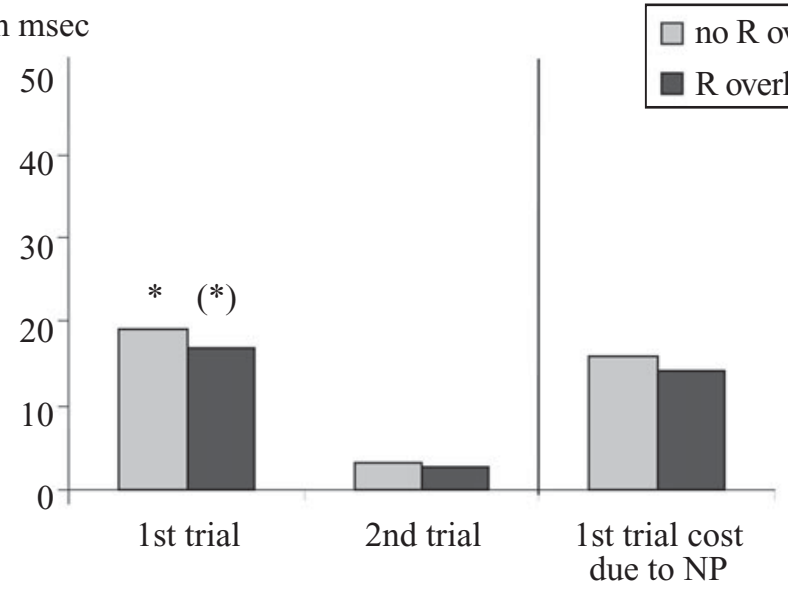

Figure 6. Experiment 2: word reading in the alternating phase. The figure shows (left panel) the two priming effects, separated for (1) first and second trials and (2) the two subject groups (no response overlap, light gray vs. response overlap, dark gray), and (right panel) the portion of the first-trial reaction time (RT) cost (or task-switching cost [TSC]) that was due to the corresponding priming component. (A) Competitor-priming (CP) component: $\{[R T(N P+C P)-R T(N P)]+[R T(C P)-R T(U)]\} / 2$, and $\{[T S C(N P+C P)-$ TSC(NP)] + [TSC(CP) - TSC(U)]\}/2. (B) Negative-priming (NP) component: $\{[R T(N P+C P)-$ RT $(C P)]+[R T(N P)-R T(U)]\} / 2$, and $\{[T S C(N P+C P)-$ TSC(CP)] + [TSC(NP) - TSC(U)] $\} / 2$. U, unprimed. One-tailed $t$ tests: **p values below .01, *p values below .05, (*)p values below .1. 
periment 2, but not in Experiment 1, can be attributed to the use of a small stimulus set. This provides strong support for an activation-level account, along the lines proposed by Malley and Strayer (1995), of the difference between Allport and Wylie's (2000) demonstration of a negative-priming component of TSC and the lack of such a component in the present Experiment 1. Finally, there was no evidence for any role of response set overlap, which suggests that stimulus set size was the only critical factor here.

\section{GENERAL DISCUSSION}

The aim of this study was to investigate whether and in what way bottom-up priming from previous processing events interacts with current top-down task readiness. In agreement with the observations of Waszak et al. (2003), we indeed found that the priming effects tested here in the word-reading task could be observed on task switch trials only, but not on task repetition trials. This interaction between current-task readiness and the effect of an earlier processing episode meant that the nominal TSC (i.e., the performance difference between task switch and task repetition trials) was greatly enhanced if the present stimulus was one that had previously been responded to in the context of a different task. As in our earlier study, this priming effect was observed even if a substantial number of trials intervened between the prime and the probe events, thus strongly supporting a retrieval-based effect.

What is more, we are now able to characterize in more detail what types of between-tasks priming are involved. (Both types of priming, we have proposed, result from involuntary retrieval of an earlier processing episode formed in the context of the competing task; Waszak et al., 2003.) In the present study, we were able to distinguish two types of retrieval-based effects: (1) betweentasks negative priming, reflecting the difficulty of responding to a target stimulus when that stimulus item had previously been ignored as a distractor in the other task, and (2) competitor priming, arising when the distractor component of the current stimulus has occurred earlier as a target item in the other task. Both experiments provided evidence for a substantial competitorpriming effect. In contrast, negative priming depended on the particular design of the task: Substantial negative priming was observed with a small stimulus set (Experiment 2) - hence, with frequent repetitions of stimulibut not with a large stimulus set (Experiment 1).

Perhaps the most striking feature of these results is that both types of long-term priming were confined to task switch trials - that is, to a switch from picture naming to word reading. The implications of these priming effects, in general, for our understanding of task-switching performance have been discussed in detail by Waszak et al. (2003) and will be only briefly considered here. As was summarized in the introduction, several earlier models of task switching attributed residual TSC to a kind of de- layed preparation, whereby completion of task set reconfiguration had to await presentation of the target stimulus (e.g., Rogers \& Monsell, 1995; Rubinstein et al., 2001). However, given all the other factors that have been shown to contribute to task switch costs, there may not be very much left, in terms of residual TSC, for such models to explain. First, in our experiments, we found that a large part of the residual TSC was due to long-term priming from previous processing episodes. Second, a number of factors other than ongoing task set reconfiguration have been demonstrated to contribute to TSC. These include first trial or restart costs (Allport \& Wylie, 2000; Altmann \& Gray, 2002; Gopher, Armony, \& Greenshpan, 2000; Wylie \& Allport, 2000), aftereffects of task set inhibition (Mayr \& Keele, 2000), and task set inertia (Allport et al., 1994; Allport \& Wylie, 1999; Altmann \& Gray, 2002; Meiran et al., 2000). Third, in another study of between-tasks priming on task switch trials, Waszak et al. (2004) have reported evidence of semantic generalization of priming from picture naming to word reading, showing that it is not even necessary for the identical stimulus items to occur in both tasks for retrieval-based interference to contribute to TSC. As long as the relative contributions of these different factors are unknown, it remains to be demonstrated whether there is anything left in residual TSC for reconfiguration models to explain.

However, our results also have important implications for our understanding of long-term event priming and of the conditions in which involuntary retrieval, based on prior S-R episodes, is liable to have significant effects on performance. This is the subject to which we will now turn.

Effects of negative priming (for reviews, see Fox, 1995; Milliken \& Tipper, 1998) and competitor priming (Warren, 1972, 1974) have been reported before, and negative priming, in particular, has been observed in a range of standard RT tasks. That is, in general, subjects do not have to be exposed to a task-switching situation in order to show these priming effects. Note, however, that the effects observed in our experiments were comparatively long-lasting: A minimum of 4 and a maximum of 14 trials intervened between prime and probe events in the present experiments, and Waszak et al. (2003) found no significant reduction in priming over lags of more than 200 trials. In contrast, most negative-priming experiments measure trial-to-trial, or at most lag-1, effects (e.g., Hommel, 1998; Malley \& Strayer, 1995; Tipper, 1985). Although there are some demonstrations of negative-priming effects that survive from minutes to days (DeSchepper \& Treisman, 1996; Lowe, 1998), there is still a paucity of data, leaving it unclear whether short-term and long-term priming reflect the same mechanisms.

As regards long-term competitor priming, the available data are even more exiguous (but see Warren 1972, 1974). In this light, it might seem surprising that the long-term priming reported here and in the earlier studies by Waszak et al. (2003) and Allport and Wylie (2000) shows such relatively large and robust effects. Why have 
such striking, long-term priming effects of this kind - in particular, priming showing substantial RT costs-not been observed before? Our answer to this question is necessarily somewhat speculative. One reason, we suggest, is that such priming effects have typically been probed within the same task as the priming event. It seems evident that there are properties of the task-switching context that make subjects exceptionally prone to interference from previously learned stimulus-task associations.

As regards the data reported here, the critical question is, therefore, the following: Why were the priming effects on word reading confined to task switch trials? We are not aware of any basic principles of episodic memory retrieval that would seem to dictate this constraint. Before addressing this question, however, we shall need to recapitulate a striking contrast between the picture-naming and the word-reading tasks, which we found in a previous study (Waszak et al., 2003, Experiment 1). In word reading, between-tasks item-specific priming was confined entirely to switch trials, as in the present study. By contrast, in the picture-naming task, stimulus items primed by prior exposure in the context of word reading showed approximately the same additional RT costs on switch and repeat trials. Similarly, in Experiment 2 of the present study, in picture naming, negatively primed stimuli tended to yield longer RTs than did competitorprimed stimuli on both switch and repeat trials. We have replicated this finding in a number of further, unpublished studies: When subjects shifted from word reading to picture naming, stimulus-task priming effects were present on task repetition trials, as well as on switch trials. How is this difference between the Stroop word and the picture tasks to be explained?

The answer to this question, we suggest, relates to the difference in relative strength of these two competing tasks. In the case of the color-word Stroop tasks (Stroop, 1935), it is generally accepted that word reading is the stronger task - that is, its underlying S-R pathway is more efficient and more practiced than the complementary color-naming pathway (MacLeod, 1991; see also MacLeod \& Dunbar, 1988). This difference in S-R pathway strength has the effect that color naming shows interference from an incongruent word stimulus, whereas word reading typically shows no interference from an incongruent ink color (MacLeod, 1991). The same asymmetry of interference is found in the picture-word Stroop tasks, as used here (Glaser \& Düngelhoff, 1984; Lupker \& Katz, 1981).

This asymmetry in the relative strength of the two tasks means that, to perform the weaker task (picture naming) in response to incongruent Stroop stimuli, a strong top-down bias favoring this task is needed. This is because the stronger task (word reading) is mediated by strong preexperimental associative links between the (word) stimuli and the corresponding vocal responses. To overcome these dominating word associations, a topdown, task-specific bias is needed, to selectively support the picture-naming response - a job typically assigned to goal representations maintained in working memory (e.g., Braver \& Cohen, 2000; Desimone \& Duncan, 1995; Kimberg \& Farah, 1993; Logan \& Gordon, 2001). For the weaker picture-naming task, this bias will be needed on all trials - that is, on task repetition, as well as on task switch, trials (and also in pure task performance). But even in pure task conditions, this top-down bias is not sufficient to prevent interference by the dominant task. The interference will be even stronger if the current stimulus was previously associated with the dominant (word-reading) task. Thus, in picture naming, itemspecific priming is observed, and it is observed on nonswitch, as well as on switch, trials.

The situation is different for the dominant task (here, word reading). Pathway strength for the dominant task normally far outweighs that for the competing picturenaming task. Hence, word reading is not liable to interference from the presence of an incongruent picture - at least, that is, under "normal" circumstances (i.e., in pure task performance and on task repetition trials). In contrast, on a task switch from picture naming to word reading, we observe massive, Stroop-like interference with word reading from an incongruent picture-that is, reverse Stroop interference (cf. Allport et al., 1994; Allport \& Wylie, 1999, 2000). (In the case of color-word Stroop tasks, the interference is, of course, from an incongruent ink color.) This observation suggests that the task set for the preceding, nondominant task (picture naming or color naming, respectively) remains active and, thus, competes with the (top-down; task-cueelicited) activations now needed for word reading, even after a long task preparation interval - a striking example of TSI. In other words, on a switch trial from picture naming to word reading, subjects are in a state similar to the one they are in on all picture-naming trials - that is, vulnerable to interference by the competing task. In this state, between-tasks interference is even further enhanced if the current stimulus has been primed in the competing task context - that is, if the stimulus-driven input, too, favors the competing task (competitor priming) and/or hampers the current task (negative priming).

In other words, in word reading, aftereffects of recently executed competing tasks - trial-to-trial TSI (Allport et al., 1994; Allport \& Wylie, 1999; Goschke, 2000)may be the precondition for the retrieval interference effects observed in the present experiments. In contrast, on task repetition trials, TSI from the preceding trial serves only to strengthen the current task set, so that task set activation is strong; hence, (on task-repetition trials) word reading is not interfered with by competing stimulustask associations.

However, note that the condition in which priming does not appear is also the condition with the shortest RTs overall. Thus, the lack of priming effects on task repetition trials might simply be an effect of word-reading RTs being at floor in this condition. The question then is the following: Would the priming effects reappear on task repetition trials if the responses were slower? This in- 
triguing question is the subject of ongoing research in our lab.

\section{Open Issues}

We are not the first to investigate priming transfer from one task context to a different one. However, all other studies that we are aware of show RT benefits from repeating an item, even in the changed task context. For example, lexical decision (word/nonword) RT is strongly facilitated by prior exposure to the same word in the context of a preceding word pronunciation task (Monsell, 1985; Scarborough, Gerard, \& Cortese, 1979), and word pronunciation RT is facilitated by prior lexical decision (Monsell, 1985). Item repetition effects with photographs of familiar faces, similarly, are found to transfer strongly from one task context to another-for example, from a facial expression judgment (smiling/not smiling?) or gender classification (male/female?) to a judgment of familiarity (Ellis, Young, \& Flude, 1990).

The finding that, in all these studies, positive longterm repetition priming occurs, even though the current task goal (or task set) is not the same as that in the original priming event, is in contrast to the results presented above and to those reported by Waszak et al. (2003). In our experiments, item priming produces an RT cost, not a benefit. This is surprising since, in the other studies mentioned above, the competing task should have been primed too, as in our experiments. Thus, the results of these studies (in all of which pure task performance was used-i.e., runs of the same task) are not easy to reconcile with the claim that long-term priming necessarily depends on retrieval of an entire event code or instance (Logan, 1988). In these earlier studies, the evidence for long-term priming based on the retrieval of a prior processing episode, including the goal, task set, response, and so forth, is therefore relatively weak. (The situation is different for short-term effects; see Hommel, 1998, 2004.) At any rate, in these earlier repetition-priming experiments, the benefit of repeating the stimulus must at least be greater than any possible interference from also retrieving the associated (but now inappropriate) task or response.

Why did we find an RT cost and not a benefit, as in all the rest of the repetition-priming literature? The answer might be easy if we had found negative priming only. The earlier studies, cited above, all used a single (bivalent) stimulus. By contrast, we used two competing stimuli (a picture and a word), so that the subjects always had to ignore one of them. Hence, in principle, the reported effect might have been based on negative priming only. However, in Experiment 2, we found both negative priming and competitor priming, and in Experiment 1 (and presumably in all five experiments by Waszak et al., 2003), we found competitor priming only. So why did repeating the picture, across tasks, yield an RT cost and not a benefit?

We see two possible tentative answers to this question. First, the retrieval of a whole processing episode might simply be relatively time consuming. If so, the priming effects we found might be negative for much the same reasons that they were restricted to switch trials (in the case of word reading). That is, it is only if there is strong and continuing task competition to delay response (as on a task switch trial in the case of word reading and as in all Stroop tasks) that prior processing episodes can be retrieved in full (i.e., including the associated task/ response). Another possible reason, which follows the same line of thought but is slightly more sophisticated, might be that activation of a competing task (either as a result of trial-to-trial TSI or because of long-term asymmetry in relative task strength) favors specifically the retrieval of task- and/or response associations consistent with that task.

The second possible answer has to do, not with the conditions of the probe task at the time of retrieval, but with the conditions affecting the priming task at the time of initial encoding. That is, it is possible that a full processing episode is compiled, including the associated task and/or response, only if there is some ambiguity as regards the current task-for example, if the same type of stimuli occur, during the course of the experiment, in different task contexts. Waszak et al. (2003) noted an interesting detail that might support this hypothesis. Experiment 3 of their study was run in two successive phases. The first phase was one of intensive picture naming (the priming phase). In the second, alternating, phase, subjects either named pictures or read words, shifting tasks as in the present study. In the alternating phase, the stimuli presented for picture naming were, exclusively, items that never appeared in the context of word reading; the item overlap occurred only between word reading in the alternating phase and picture naming in the initial priming phase. In the course of pilot studies, however, it was found that task priming from picture naming to word reading with this procedure was obtained only if the priming phase included also a small proportion of wordreading trials. Maybe these intercalated word-reading trials established the task ambiguity necessary for full processing episodes to be encoded. On the other hand, the experiments by Hommel (1998) demonstrate that shortterm effects of episodic encoding and retrieval can be found even under pure task conditions. More research is needed to give a clear answer to this intriguing question.

\section{REFERENCES}

Allport, D. A. (1987). Selection for action: Some behavioral and neurophysiological considerations of attention and action. In H. Heuer \& A. F. Sanders (Eds.), Perspectives on perception and action (pp. 395419). Hillsdale, NJ: Erlbaum.

Allport, D. A., Styles, E. A., \& Hsieh, S. (1994). Shifting intentional set: Exploring the dynamic control of tasks. In C. Umiltà \& M. Moscovitch (Eds.), Attention and performance XV: Conscious and nonconscious information processing (pp. 421-452). Cambridge, MA: MIT Press, Bradford Books.

Allport, D. A., Tipper, S. P., \& Chmiel, N. R. J. (1985). Perceptual integration and postcategorical filtering. In M. I. Posner \& O. S. M. Marin (Eds.), Attention and performance XI (pp. 107-132). Hillsdale, NJ: Erlbaum.

AllPORT, D. A., \& Wylie, G. (1999). Task-switching: Positive and neg- 
ative priming of task-set. In G. W. Humphreys, J. Duncan, \& A. M. Treisman (Eds.), Attention, space and action: Studies in cognitive neuroscience (pp. 273-296). Oxford: Oxford University Press.

Allport, D. A., \& Wylie, G. (2000). "Task-switching" stimulusresponse bindings and negative priming. In S. Monsell \& J. Driver (Eds.), Control of cognitive processes: Attention and performance XVIII (pp. 35-70). Cambridge, MA: MIT Press.

Altmann, E. M., \& Gray, W. D. (2002). Forgetting to remember: The functional relationship of decay and interference. Psychological Science, 13, 27-33.

ARRINGTON, C. M., \& Logan, G. D. (2004). Episodic and semantic components of the compound-stimulus strategy in the explicit taskcuing procedure. Memory \& Cognition, 32, 965-978.

Braver, T. S., \& Cohen, J. D. (2000). On the control of control: The role of dopamine in regulating prefrontal function and working memory. In S. Monsell \& J. Driver (Eds.), Control of cognitive processes: Attention and performance XVIII (pp. 713-737). Cambridge, MA: MIT Press.

Burnage, G. (1990). CELEX: A guide for users. Nijmegen: SSN.

DeSchepper, B., \& Treisman, A. (1996). Visual memory for novel shapes: Implicit coding without attention. Journal of Experimental Psychology: Learning, Memory, \& Cognition, 22, 27-47.

Desimone, R., \& Duncan, J. (1995). Neural mechanisms of selective visual attention. Annual Review of Neuroscience, 18, 193-222.

Ellis, A. W., Young, A. W., \& Flude, B. M. (1990). Repetition priming and face processing: Priming occurs within the system that responds to the identity of a face. Quarterly Journal of Experimental Psychology, 42A, 495-512.

FAGOT, C. (1994). Chronometric investigation of task switching. Unpublished doctoral dissertation, University of California, San Diego.

Fox, E. (1995). Negative priming from ignored distractors in visual selection: A review. Psychonomic Bulletin \& Review, 2, 145-173.

Glaser, W. R., \& DÜNGELHOFF, F.-J. (1984). The time course of pictureword interference. Journal of Experimental Psychology: Human Perception \& Performance, 10, 640-654.

GOPHER, D., ARMONY, L., \& GREENSHPAN, Y. (2000). Switching tasks and attention policies. Journal of Experimental Psychology: General, 129, 308-339.

GoschKE, T. (2000). Involuntary persistence and intentional reconfiguration in task-set switching. In S. Monsell \& J. Driver (Eds.), Attention and performance XVIII: Control of cognitive processes (pp. 331355). Cambridge, MA: MIT Press.

Hommel, B. (1998). Event files: Evidence for automatic integration of stimulus-response episodes. Visual Cognition, 5, 183-216.

Hommel, B. (2004). Feature integration across perception and action: Event files affect response choice. Manuscript submitted for publication.

Hommel, B., Pösse, B., \& WaszaK, F. (2000). Contextualization in perception and action. Psychologica Belgica, 40, 227-245.

KimberG, D. Y., \& FARAH, M. J. (1993). A unified account of cognitive impairments following frontal lobe damage: The role of working memory in complex, organized behavior. Journal of Experimental Psychology: General, 122, 411-428.

KOCH, I., \& ALLPORT, A. (in press). Cue-based preparation and stimulusbased priming of tasks in task switching. Memory \& Cognition.

LogAN, G. D. (1988). Toward an instance theory of automatization. Psychological Review, 95, 492-527.

LoGAN, G. D., \& GoRDON, R. D. (2001). Executive control of visual attention in dual-task situations. Psychological Review, 108, 393-434.

Lowe, D. (1998). Long-term positive and negative identity priming: Evidence for episodic retrieval. Memory \& Cognition, 26, 435-443.

LUPKER, S. J., \& KATZ, A. N. (1981). Input, decision, and response factors in picture-word interference. Journal of Experimental Psychology: Human Learning \& Memory, 7, 269-282.

MACLEOD, C. M. (1991). Half a century of research on the Stroop effect: An integrative review. Psychological Bulletin, 109, 163-203.

MacLeod, C. M., \& Dunbar, K. (1988). Training and Stroop-like interference: Evidence for a continuum of automaticity. Journal of Experimental Psychology: Learning, Memory, \& Cognition, 14, 126-135.

MALLEY, G. B., \& StraYeR, D. L. (1995). Effect of stimulus repetition on positive and negative identity priming. Perception \& Psychophysics, 57, 657-667.
May, C. P., Kane, M. J., \& Hasher, L. (1995). Determinants of negative priming. Psychological Bulletin, 118, 35-54.

MAYR, U., \& KeELE, S. W. (2000). Changing internal constraints on action: The role of backward inhibition. Journal of Experimental Psychology: General, 129, 4-26.

MEIRAN, N. (1996). Reconfiguration of processing mode prior to task performance. Journal of Experimental Psychology: Learning, Memory, \& Cognition, 22, 1423-1442.

MeIRAN, N. (2000). Modeling cognitive control in task-switching. Psychological Research, 63, 234-249.

MeIran, N., ChOREv, Z., \& SAPIR, A. (2000). Component processes in task switching. Cognitive Psychology, 41, 211-253.

Milliken, B., \& TiPPER, S. P. (1998). Attention and inhibition. In H. Pashler (Ed.), Attention (pp. 191-221). San Diego: Psychology Press.

Monsell, S. (1985). Repetition and the lexicon. In A. W. Ellis (Ed.), Progress in the psychology of language (Vol. 2, pp. 147-195). London: Erlbaum.

NeILL, W. T. (1977). Inhibitory and facilitatory processes in selective attention. Journal of Experimental Psychology: Human Perception \& Performance, $\mathbf{3}, 444-450$.

NEILL, W. T. (1997). Episodic retrieval in negative priming and repetition priming. Journal of Experimental Psychology: Learning, Memory, \& Cognition, 23, 1291-1305.

NeILL, W. T., \& VALDES, L. A. (1992). Persistence of negative priming: Steady state or decay? Journal of Experimental Psychology: Learning, Memory, \& Cognition, 18, 565-576.

Neill, W. T., Valdes, L. A., Terry, K. M., \& Gorfein, D. S. (1992). Persistence of negative priming: II. Evidence for episodic trace retrieval. Journal of Experimental Psychology: Learning, Memory, \& Cognition, 18, 993-1000.

ROGERS, R. D., \& MONSELL, S. (1995). Costs of a predictable switch between simple cognitive tasks. Journal of Experimental Psychology: General, 124, 207-231.

Rubinstein, J., Meyer, D. E., \& Evans, J. E. (2001). Executive control of cognitive processes in task switching. Journal of Experimental Psychology: Human Perception \& Performance, 27, 763-797.

Ruthruff, E., Remington, R. W., \& Johnston, J. C. (2001). Switching between simple cognitive tasks: The interaction of top-down and bottom-up factors. Journal of Experimental Psychology: Human Perception \& Performance, 27, 1404-1419.

Scarborough, D. L., Gerard, L., \& Cortese, C. (1979). Accessing lexical memory: The transfer of word repetition effects across task and modality. Memory \& Cognition, 7, 3-12.

SNODGrass, J. G., \& VANDERWART, M. (1980). A standardized set of 260 pictures: Norms for name agreement, image agreement, familiarity, and visual complexity. Journal of Experimental Psychology: Human Learning \& Memory, 6, 174-215.

SoHN, M.-H., \& ANDERSON, J. R. (2001). Task preparation and task repetition: Two-component model of task switching. Journal of Experimental Psychology: General, 130, 764-778.

SoHN, M.-H., \& CARLSON, R. A. (2000). Effects of repetition and foreknowledge in task-set reconfiguration. Journal of Experimental Psychology: Learning, Memory, \& Cognition, 26, 1445-1460.

StRAYER, D. L., \& GRISON, S. (1999). Negative identity priming is contingent on stimulus repetition. Journal of Experimental Psychology: Human Perception \& Performance, 25, 24-38.

STROOP, J. R. (1935). Studies of interference in serial verbal reactions. Journal of Experimental Psychology, 18, 643-662.

TIPPER, S. P. (1985). The negative priming effect: Inhibitory priming by ignored objects. Quarterly Journal of Experimental Psychology, 37A, 571-590.

TipPer, S. P., \& Cranston, M. (1985). Selective attention and priming: Inhibitory and facilitatory effects of ignored primes. Quarterly Journal of Experimental Psychology, 37A, 591-611.

Tipper, S. P., Weaver, B., \& Houghton, G. (1994). Behavioural goals determine inhibitory mechanisms of selective attention. Quarterly Journal of Experimental Psychology, 47A, 809-840.

WARREN, R. E. (1972). Stimulus encoding and memory. Journal of Experimental Psychology, 94, 90-100.

WARren, R. E. (1974). Association, directionality and stimulus encoding. Journal of Experimental Psychology, 102, 151-158. 
WaszaK, F., Hommel, B., \& Allport, A. (2003). Task-switching and long-term priming: Role of episodic stimulus-task bindings in taskshift costs. Cognitive Psychology, 46, 361-413.

WaszaK, F., Hommel, B., \& Allport, A. (2004). Semantic generalization of stimulus-task bindings. Psychonomic Bulletin \& Review, 11, 1027-1033.

WYLIE, G., \& ALLPORT, A. (2000). Task switching and the measurement of "switch costs." Psychological Research, 63, 212-233.

\section{NOTES}

1. In order to reduce possible semantic priming between the different stimulus sets, the semantic overlap between items of the three subsets was minimized. This was important because semantic overlap between the item sets would "pollute" the RTs with semantic priming. That is, items considered to be unprimed because they were not presented in picture naming might, in fact, be semantically primed because semantically related items have been presented in picture naming. Data on this important issue will be published elsewhere (Waszak et al., 2004). Moreover, words and pictures within a set were also chosen to have minimal semantic overlap. Minimal semantic overlap between pictures and words within each set ensured that the semantic overlap of the individual pairings of picture and word elements (which may affect RTs and increase the effect of that processing episode on subsequent processing episodes) was the same in all four priming conditions. A by-product of this procedure was that we maximized the semantic overlap between pictures with pictures and between words with words within item subsets. This was necessary because there was only a limited number of line drawings.

2. It is a common finding that under some conditions (e.g., speed stress or rapid pattern masking of prime distractors), ignored distractors produce facilitation on the probe trial (e.g., Allport, Tipper, \& Chmiel, 1985). In the following, we will argue that there was no need to inhibit the distractor words in Experiment 1, so that the small positive priming may reflect the initial activation of the distractor words.

3. As in Experiment 1, for the group of subjects without response set overlap, the semantic overlap between the items of the three subsets was minimized, and the pictures and words were also chosen to have minimal within-set semantic overlap. This was done to ensure equal (viz., minimal) semantic priming between subsets and equal (viz., minimal) semantic overlap of the individual pairings of picture and word elements in all four priming conditions. This was perforce impossible for the group of subjects with response set overlap. To ensure equal semantic priming between subsets and equal within-conjunction semantic overlap for this group of subjects too, 12 concepts (four items in each of three subsets) of the same semantic category were chosen. That is, semantic priming between subsets and within-conjunction overlap were maximal.

(Manuscript received January 22, 2004; revision accepted for publication July 23, 2004.) 